\title{
Preoperative cerebral ischemic lesions predict physical health status after on-pump coronary artery bypass surgery
}

\author{
Lars Mathisen, RN, MS, ${ }^{a, b}$ Marit Helen Andersen, RN, MSN, ${ }^{c}$ Per Kristian Hol, MD, ${ }^{d}$ Bjørn Tennøe, MD, ${ }^{e}$ \\ Christian Lund, MD, ${ }^{f}$ David Russell, MD, PhD, FRCPE, ${ }^{f}$ Runar Lundblad, MD, PhD, ${ }^{\mathrm{b}}$ Steinar Halvorsen, MD, ${ }^{d}$ \\ Astrid Klopstad Wahl, RN, PhD, ${ }^{g}$ Berit Rokne Hanestad, RN, PhD, ${ }^{\mathrm{h}}$ and Erik Fosse, MD, PhD ${ }^{\mathrm{d}}$
}

From the University of Oslo, Faculty Division Rikshospitalet/The Interventional Centre, ${ }^{a}$ the Department of Thoracic and Cardiovascular Surgery, ${ }^{\mathrm{b}}$ the Department of Surgery, ${ }^{\mathrm{c}}$ The Interventional Centre, ${ }^{\mathrm{d}}$ the Department of Radiology, ${ }^{\mathrm{e}}$ the Department of Neurology, ${ }^{\mathrm{f}}$ The University Hospital Rikshospitalet-Radiumhospitalet Trust, Oslo, Norway; the Oslo University College of Nursing, ${ }^{\mathrm{g}}$ Oslo, Norway; and The Institute of Public Health/Faculty of Social Sciences, ${ }^{\mathrm{h}}$ University of Bergen, Norway.

Supported by The Research Council of Norway (NFR2004-160347), The Norwegian Nurses' Association, The Norwegian Association of Heart and Lung Patients, and The Center for Patient Participation and Nursing Research at The University Hospital Rikshospitalet-Radiumhospitalet Trust.

Received for publication April 5, 2005; revisions received July 29, 2005; accepted for publication Aug 15, 2005.

Address for reprints: Lars Mathisen, RN, MS, University of Oslo, Faculty Division Rikshospitalet, The Interventional Centre, or the Department of Thoracic and Cardiovascular Surgery, The University Hospital RikshospitaletRadiumhospitalet Trust, Sognsvannsveien 20, 0027 Oslo, Norway (E-mail: lars.mathisen@ medisin.uio.no).

J Thorac Cardiovasc Surg 2005;130:1691-7

$0022-5223 / \$ 30.00$

Copyright () 2005 by The American Association for Thoracic Surgery

doi:10.1016/j.jtcvs.2005.08.008
Background: Risk assessment is integral to patient selection and counseling before coronary artery revascularization. We studied the predictive ability of cerebral magnetic resonance imaging of preoperative and postoperative cerebral ischemic injury on self-reported physical and mental health at 3 months after coronary artery bypass surgery with or without use of cardiopulmonary bypass.

Methods: In a prospective clinical trial comparing on-pump and off-pump surgery, 120 patients responded to a questionnaire for self-report of angina (Canadian Cardiovascular Society scale) and physical and mental health status (Short Form 36) at baseline before preoperative cerebral magnetic resonance imaging. Preoperative sets of both magnetic resonance imaging and self-assessments were available for $103(85.8 \%)$ patients. These patients were grouped according to classification of preoperative cerebral magnetic resonance imaging findings. Analysis of covariance determined the association of (1) preoperative magnetic resonance imaging status, (2) new postoperative cerebral lesions, and (3) actual use of cardiopulmonary bypass to physical and mental health.

Results: At 3 months after surgical intervention, 98 of 103 patients completed follow-up. The analysis revealed an interaction effect of preoperative cerebral ischemic injury and use of cardiopulmonary bypass on physical health $(\mathrm{F}=9.07$, $P=.003$ ) independent of age. No independent effects on health status were found of baseline magnetic resonance imaging or new cerebral lesions at 3 months.

Conclusions: This study strongly suggests that the combination of preoperative cerebral ischemic injury and use of cardiopulmonary bypass can predict postoperative health status at 3 months. Cerebral magnetic resonance imaging might be a more specific indicator than age for preoperative assessment of vulnerability or resilience during rehabilitation after on-pump cardiac surgery.

$\mathrm{P}$ atient-reported outcomes, the subjective and multidimensional assessments of the effect of disease and its treatment, ${ }^{1}$ remain essential to understand and compare the processes and outcomes of health care. The association between self-reported health status and the neurologic effect of cardiac surgery is not fully understood, possibly because prior research in this field has focused on the relationship between subjective and objective measures of health ${ }^{2-4}$ rather than correlation to their common causal indicators, such as signs of cerebral injury visualized by means of cerebral magnetic resonance imaging (MRI).

Subclinical cerebrovascular disease is prevalent in the adult population and even more so in the patient population with coronary arteriosclerosis. Epidemiologic research reports $15.3 \%$ overall prevalence of infarct-like lesions on cerebral MRI in the 55- to 72-year age group, 10 times the prevalence of stroke. ${ }^{5}$ In the population older than 65 years, frail health has been shown to correlate with infarct-like lesions, 


\section{Abbreviations and Acronyms \\ $\mathrm{CI}=$ confidence interval \\ MRI = magnetic resonance imaging \\ SF-36 = 36-item Medical Outcomes Study Short Form \\ 36}

as well as cardiovascular disease. ${ }^{6}$ A study of 15 patients undergoing coronary artery bypass revealed that 14 had preoperative MRI abnormalities, with 4 patients showing new cerebral lesions after the operation. ${ }^{7}$ Others have reported from $21 \%$ to $45 \%$ presence of acute postoperative cerebral lesions on MRI without overt clinical signs of neurologic deficit. ${ }^{8-10}$ However, patient-reported outcomes have, to our knowledge, not been published in relation to MRI findings in this patient population. For the present study, we planned a secondary analysis of data from a clinical trial of 120 patients undergoing off-pump versus conventional on-pump coronary artery bypass surgery. Previously reported conclusions from this trial include similar perioperative outcomes and 3-month graft patency rates and higher counts of intraoperative cerebral emboli in on-pump patients. $^{11,12}$

Given the prevalence of subclinical cerebrovascular disease and theory suggesting a causal pathway from clinical variables to self-reported health status, ${ }^{13}$ the purpose of the present study was to assess the predictive ability of preoperative and postoperative cerebral MRI findings on physical and mental health reported by patients at 3 months after bypass surgery. We hypothesized a priori that evidence of cerebral ischemic injury would identify patients at higher risk and that new postoperative cerebral lesions or the use of intraoperative cardiopulmonary bypass would modify outcomes.

\section{Patients and Methods}

\section{Sample}

Data stem from a clinical trial in which 120 patients aged between 40 and 80 years with stable angina pectoris were randomized to elective on- or off-pump coronary artery bypass surgery. Exclusion criteria were a left ventricular ejection fraction of less than $30 \%$, a serum creatinine level of greater than $200 \mathrm{mmol} / \mathrm{L}$, and lack of ability to read, write, or communicate verbally in Norwegian. In the present study the analysis was based on available patients completing the combination of cerebral MRI and self-reported health status assessments before surgical intervention and at 3 months postoperatively.

\section{Procedure}

The study protocol was approved by the regional ethics committee. After providing written and informed consent, the patients responded to a health status questionnaire administered by one of the authors. The procedure for all self-assessments was standardized and scheduled before further diagnostics (including clinical neu- rologic and cerebral MRI examination), before the operation, and at 3 months after the operation.

The diagnostic and surgical procedures, including management of anesthesia and cardiopulmonary bypass, have earlier been described in detail. ${ }^{11,12}$ Briefly summarized, all operations were performed after achievement of balanced opiate, barbiturate, and inhalation anesthesia. The internal thoracic artery was used for revascularization of the left anterior descending coronary artery, and saphenous vein grafts were used for all other vessels. The distal anastomoses were performed first, and the proximal anastomoses were performed successively thereafter with a partial aortic clamp. On-table graft angiography was performed, followed by graft revision if questionable quality of the anastomosis or the graft was revealed.

In the on-pump group the bypass circuit was tip-to-tip heparin coated with the Duraflo II heparin surface (Bentley/Baxter, Uden, the Netherlands), and activated coagulation time was maintained at greater than 480 seconds. All operations were performed with moderate general hypothermia $\left(28^{\circ} \mathrm{C}-32^{\circ} \mathrm{C}\right)$ and cold St Thomas antegrade cardioplegic solution. Bypass management included membrane oxygenators, arterial line filters, use of a roller pump and cardiotomy suction, nonpulsatile flow of $2.4 \mathrm{~L} / \mathrm{min}$ per square meter, and a target mean arterial pressure of greater than $50 \mathrm{~mm} \mathrm{Hg}$.

In the beating-heart patients heparin $(1 \mathrm{mg} / \mathrm{kg})$ was administered during takedown of the internal thoracic artery, and activated coagulation time was maintained at greater than 250 seconds. The distal anastomoses were performed with the use of snares (Gore Tex 3-0; W.L.Gore \& Associates, Flagstaff, Ariz) and stabilizers (Octopus I and II, Medtronics, Minneapolis, Minn) combined with deep pericardial retraction sutures and, as needed, an apical suction device (Starfish; Medtronics, Minneapolis, Minn). A carbon dioxide blower (Ethicon Cardiovations, Summerville, NJ) was used to obtain a bloodless anastomosis field.

\section{Variables}

Physical and mental health. The 36-item Medical Outcomes Study Short Form 36 (SF-36) reflects health status during the past 4 weeks. ${ }^{14}$ Two summary scores, physical and mental health, are calculated from 8 subscales ranging from 0 to 100 , with higher scores indicating better health. ${ }^{15}$ After standardization and linear transformation, the summary scores compare with a population reference mean of 50 and a standard deviation of 10 , so that each point on the scale represents one tenth of a standard deviation. SF-36 subscales loading most heavily on the mental component include vitality, emotional role functioning, social functioning, and mental health. The physical component represents physical functioning, physical role functioning, bodily pain, and general health.

MRI. Cerebral MRI was performed with a 1.5-T scanner with axial proton-density and T2-weighted turbospin-echocardiography with 5-mm slice thickness and 1.5-mm slice intergap. The repetition time was $2200 \mathrm{~ms}$, and the echocardiographic time was $14 \mathrm{~ms}$ for proton and $85 \mathrm{~ms}$ for T2. The images were evaluated by an experienced neuroradiologist blinded to the patients' clinical status and use of cardiopulmonary bypass. The presence of preoperative cerebral ischemic lesions was scored as absent, borderline $(<5$ $\mathrm{mm}$ ), or pathologic ( $\geq 5 \mathrm{~mm}$ ). At 3 months' follow-up MRI, new lesions were defined as one or more new cerebral lesions larger than $2 \mathrm{~mm}$ that were not present at the preoperative examination. 
Intraoperative and immediate postoperative events. Patients converted from off-pump surgery to use of cardiopulmonary bypass, either because of hemodynamic instability or for technical reasons, were identified by using a dichotomous variable. Manual anesthesia records were reviewed to determine preanesthetic and intraoperative systolic blood pressure, use of inotropes beyond routine administration, intraoperative events, and, if applicable, mean arterial pressure during cardiopulmonary bypass. Intensive care flowcharts were reviewed to identify the use of intra-aortic balloon pumping or incidents of mean arterial blood pressure of less than $60 \mathrm{~mm} \mathrm{Hg}$ on the day of the operation.

Postoperative course. Dichotomous variables were entered for atrial fibrillation, pulmonary complications, and leg or chest wound infection, with data collected from physician notes at the planned in-patient follow-up. Patients' comments on questionnaires and field notes during interviews were screened for any persisting problems not covered in the self-assessment questionnaire, where pain, sleep quality, and sexual difficulties were queried. The number of significant life events since the operation was assessed by 8 items representing stressors, such as the loss of a spouse.

Angina. The Canadian Cardiovascular Society scale ${ }^{16}$ was used for self-report. Scores at 3 months were dichotomized by comparison with baseline level to determine improvement versus no improvement or worsening of angina.

\section{Statistical Analysis}

The SF-36 scoring manuals directed handling of missing items and subscale and summary score calculations. ${ }^{15,17}$ The Norwegian National Health Survey of $2002(n=6723)$ provided population reference values for norm-based scoring weighted for age and sex to match the sample.

Patient-reported outcomes on the basis of randomization to the on- or off-pump procedure (intention-to-treat analysis) have previously been reported. ${ }^{18}$ For purposes of the present study, use of cardiopulmonary bypass was defined as actual use regardless of randomization; a patient crossing over from off- to on-pump surgery was classified in the on-pump group, and the influence of conversion was examined during analysis.

After visual inspection of health status box plots, patients with borderline and pathologic MRI findings were clustered, leaving patients with normal MRI results at baseline to constitute a group expected to prove resilient to the burden of surgical intervention. The a priori hypotheses were tested in covariance models, where we included sex and improvement of angina as factors and baseline health status as a linear covariate, with additional postoperative factors if the $P$ value of bivariate correlation to 3 months' health status was less than .05. As we expected the correlation of age and health status to increase after successful surgical intervention, approaching characteristics of a normal population, the final covariance models were challenged by adding age as a predictor variable. The level of statistical significance was set at an $\alpha$ value of .05. Data were handled with SPSS v.12.0 (SPSS Inc, Chicago, Ill).

\section{Results}

Among 120 patients recruited to the clinical trial, 102 patients completed cerebral MRI, as well as the self-report of
TABLE 1. Baseline and intraoperative characteristics of the patient population

\begin{tabular}{|c|c|c|c|}
\hline & $\begin{array}{c}\text { Included in } \\
\text { analysis } \\
(n=103)\end{array}$ & $\begin{array}{l}\text { Not included } \\
\quad(n=17)\end{array}$ & $P$ value \\
\hline Age, y & $64.5(8.10)$ & $64.2(7.42)$ & $.865^{*}$ \\
\hline Male sex & $82(79.6 \%)$ & $12(70.6 \%)$ & $.403 \dagger$ \\
\hline Physical health/PCS & $41.7(8.33)$ & $42.5(8.70)$ & $.726^{*}$ \\
\hline Mental health/MCS & $42.5(11.39)$ & $45.3(12.10)$ & $.381^{*}$ \\
\hline Angina class, self-report & & & $.410 \ddagger$ \\
\hline No angina & $9(8.7 \%)$ & $1(5.9 \%)$ & \\
\hline 1 & $22(21.4 \%)$ & $7(41.2 \%)$ & \\
\hline II & $37(35.9 \%)$ & $6(35.3 \%)$ & \\
\hline III & $22(21.4 \%)$ & $2(11.8 \%)$ & \\
\hline IV & $9(8.7 \%)$ & 0 & \\
\hline Missing & $4(3.9 \%)$ & $1(5.9 \%)$ & \\
\hline Education, y & $10.1(2.79)$ & $11.7(3.57)$ & $.036^{*}$ \\
\hline Living alone & $16(15.5 \%)$ & $2(11.8 \%)$ & $1.000 \ddagger$ \\
\hline Body mass index, $\mathrm{kg} / \mathrm{m}^{2}$ & $26.7(3.30)$ & $26.7(3.81)$ & $.968 *$ \\
\hline Smoking tobacco daily & $18(17.5 \%)$ & $4(23.5 \%)$ & $.513 \ddagger$ \\
\hline Ejection fraction, $\%$ & $71.2(10.19)$ & $71.7(13.16)$ & $.873^{*}$ \\
\hline $\begin{array}{l}\text { Previous myocardial } \\
\text { infarction }\end{array}$ & $46(44.7 \%)$ & $9(52.9 \%)$ & $.526 \dagger$ \\
\hline $\begin{array}{l}\text { Previous transitory ischemic } \\
\text { attack }\end{array}$ & $4(3.9 \%)$ & $1(5.9 \%)$ & $.541 \ddagger$ \\
\hline Previous stroke & $4(3.9 \%)$ & 0 & $1.000 \ddagger$ \\
\hline Serum creatinine, $\mathrm{mmol} / \mathrm{L}$ & $97.4(16.05)$ & $96.7(16.47)$ & $.864^{*}$ \\
\hline Hypertension & $42(40.8 \%)$ & $9(52.9 \%)$ & $.347 \dagger$ \\
\hline Diabetes & $15(14.6 \%)$ & $5(29.4 \%)$ & $.128 \dagger$ \\
\hline Obstructive lung disease & $12(11.7 \%)$ & $3(17.6 \%)$ & $.445 \ddagger$ \\
\hline Duration of surgery, min & $174.9(49.99)$ & $189.4(70.56)$ & $.301^{*}$ \\
\hline No. of distal anastomoses & $3(1-5)$ & $3(1-5)$ & $.429 \S$ \\
\hline Procedures with CPB & $56(54.4 \%)$ & $11(64.7 \%)$ & $.427 \dagger$ \\
\hline Duration of $\mathrm{CPB}$, min & $62.3(25.12)$ & $73.6(22.38)$ & $.167^{*}$ \\
\hline Cross-over to CPB & $4(3.9 \%)$ & $3(17.6 \%)$ & $.058 \ddagger$ \\
\hline
\end{tabular}

Values are presented as counts (percentage), means (standard deviation), or medians (minimum-maximum). PCS, Physical Component Summary of the Short Form 36 Health Survey; MCS, Mental Component Summary of the Short Form 36 Health Survey; CPB, cardiopulmonary bypass. * $t$ Test. $\dagger \chi^{2}$ test. ‡Fisher exact test. §Mann-Whitney $U$ test.

physical and mental health before the operation. We also included one patient who had normal MRI results at followup and for whom we assumed normal MRI results at baseline, for a total of 103 patients analyzed (Table 1). Reasons for exclusion of 17 patients from analysis were as follows. Two patients withdrew from the study for personal reasons. Two patients died in the early postoperative period (one after a stroke and the other suddenly on postoperative day 11). Cerebral MRI results were not obtained at baseline or follow-up from 11 patients, either for practical reasons or because of claustrophobia. The questionnaires from 2 patients were incomplete for summary score calculations. Apart from mean duration of education, the groups included versus excluded from analysis were comparable. We found 
TABLE 2. Baseline and 3-month physical and mental health summary scores on the basis of cerebral MRI classification

\begin{tabular}{|c|c|c|c|c|c|c|c|}
\hline \multirow[b]{2}{*}{ Baseline MRI } & \multirow[b]{2}{*}{ n } & \multicolumn{2}{|c|}{ Physical health } & \multirow[b]{2}{*}{$P$ value* } & \multicolumn{2}{|c|}{ Mental health } & \multirow[b]{2}{*}{$P$ value } \\
\hline & & Baseline & $3 \mathrm{mo}$ & & Baseline & $3 \mathrm{mo}$ & \\
\hline Normal & 19 & $40.1(7.34)$ & $47.2(9.89)$ & .004 & 44.1 (9.99) & $50.5(8.47)$ & .024 \\
\hline Borderline & 38 & $41.3(8.67)$ & $44.5(7.80)$ & .039 & $42.1(11.61)$ & 47.5 (8.55) & .001 \\
\hline Pathologic & 46 & 42.7 (8.48) & 46.7 (8.59) & .002 & $42.1(11.90)$ & $48.2(8.71)$ & .002 \\
\hline
\end{tabular}

Values are presented as means (standard deviation). MRI, Magnetic resonance imaging. *A paired $t$ test was used for comparison within groups.

a strong linear relationship between age and the existence of cerebral lesions at baseline (Spearman rho $=0.568, P<$ $.000)$. However, the correlation of age or MRI findings to baseline physical or mental health was not significant $(P=$ .399 for age and physical health, $P=.446$ for age and mental health; $P=.241$ for MRI class and physical health, $P=.623$ for MRI class and mental health).

At 3 months after the operation, preoperative and postoperative health status demonstrated improvement across groups defined by MRI status (Table 2), which is similar to overall effects that have previously been reported. ${ }^{18}$ In the present sample improvement of angina was experienced by $77(74.8 \%)$ of the respondents and was significantly related to physical health at 3 months $(t=2.38, P=.019)$ but not to mental health $(t=0.60, P=.548)$. Of $12(11.7 \%)$ patients demonstrating new cerebral lesions, only 1 had a normal MRI result at baseline. One patient had experienced a stroke, confirmed by means of cerebral MRI, but achieved complete neurologic recovery within 3 months. There were 6 patients with sternal wound infection and 7 with leg incision infection. The median number of significant life events was 0 , ranging from 0 to 3 . Chest wound infection $(t=3.12, P=.002)$ and 2 or more stressful life events $(t=$ $2.12, P=.037)$ correlated significantly to physical health at 3 months but not to mental health.

\section{Physical Health}

Baseline cerebral MRI status ( $\mathrm{F}=1.265, P=.264)$ or new postoperative cerebral lesions $(\mathrm{F}=3.230, P=.076)$ did not demonstrate independent predictive ability on physical health in models that included baseline physical health, sex, improved angina, and chest wound infection. However, the interaction effect of baseline MRI status and use of intraoperative cardiopulmonary bypass on physical health was significant (Table 3), implying that the effect of cardiopulmonary bypass was conditional on baseline MRI status. This interaction effect is shown in Figure 1, using physical health change scores from baseline. The finding remained statistically significant when including age or education as a covariate, and the model also remained stable when controlling for the effect of crossing over from off-pump to on-pump surgery. Duration of cardiopulmonary bypass and management of hemodynamics was comparable within the on-pump group (Table 4). The estimated marginal means of physical health total scores, adjusting for baseline variation, were 45.6 points (95\% confidence interval [CI], 40.1-51.0) for normal baseline MRI results versus 37.4 points $(95 \% \mathrm{CI}$, 33.3-41.4) for borderline or pathologic baseline MRI results for on-pump patients. For off-pump patients, the corresponding estimates were 36.5 points $(95 \%$ CI, 30.7-42.3) versus 39.4 points $(95 \% \mathrm{CI}, 35.0-43.8)$.

\section{Mental Health}

Baseline cerebral MRI status ( $\mathrm{F}=0.637, P=.427)$, new postoperative cerebral lesions ( $\mathrm{F}=1.237, P=.269)$, or an interaction effect of baseline MRI status and use of intraoperative cardiopulmonary bypass $(\mathrm{F}=0.188, P=.666)$ was not predictive of mental health. These 3 models all included the following variables: baseline mental health status, sex, and improved angina.

\section{Discussion}

In this study preoperative MRI evidence of cerebral ischemic injury combined with the use of cardiopulmonary bypass was associated with physical health status at 3 months after coronary artery bypass surgery.

TABLE 3. Predictors of physical health at 3 months after surgical intervention

\begin{tabular}{lrr}
\hline Predictor variables & F & P value \\
\hline Baseline cerebral MRI, independent effect & & \\
$\quad$ (borderline or pathologic coded 1)* & 2.053 & .155 \\
Use of CPB, independent effect* & 3.379 & .069 \\
Interaction of baseline MRI and use of CPB & 9.069 & .003 \\
Sex & 3.340 & .071 \\
Postoperative chest wound infection & 8.221 & .005 \\
Improved angina & 11.598 & .001 \\
Baseline physical health & 18.705 & .000 \\
\hline
\end{tabular}

In this analysis of covariance model, the amount of variance in total physical health scores explained (adjusted $R^{2}$ ) was $38.7 \%$. All predictor variables carried $1 \mathrm{df}$. Age, education, and life events were discarded from the final model. $M R I$, Magnetic resonance imaging; $C P B$, cardiopulmonary bypass. *Values of the interaction components were centered to a mean of 0 . A model including the same predictor variables, uncentered and without the interaction term, showed significant associations for baseline physical health $(\mathrm{F}=19.41, P<.000)$, relief of angina $(\mathrm{F}=12.07, P=.001)$, and chest wound infection $(\mathrm{F}=4.62, P=.034)$ but not for $\operatorname{sex}(\mathrm{F}=2.71$, $P=.103)$, baseline MRI status $(\mathrm{F}=1.18, P=.280)$, or cardiopulmonary bypass $(\mathrm{F}=0.02, P=.904)$. 


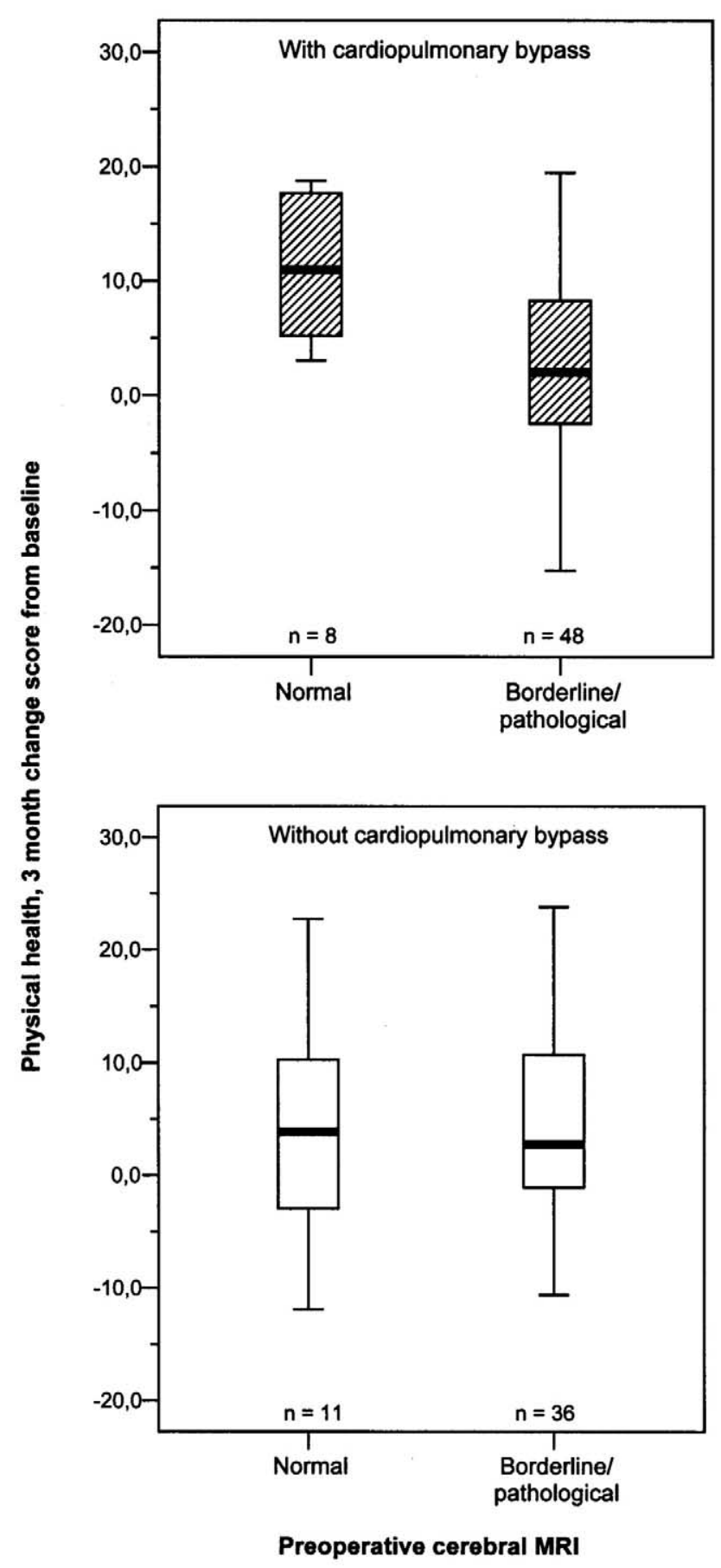

Figure 1. Physical health at 3 months after surgical intervention: change scores from baseline. Change scores are calculated by subtracting preoperative scores from 3-month total scores. Boxes represent interquartile ranges, and horizontal bands indicate median values. $M R I$, Magnetic resonance imaging.

For on-pump procedures, no apparent explanation for differences in health status emerged from chart review of intraoperative and postoperative hemodynamics (Table 4). We controlled statistically for conversion from the off-
TABLE 4. Cardiopulmonary bypass group only, intraoperative and postoperative variables

\begin{tabular}{lcc}
\hline & \multicolumn{2}{c}{ Baseline cerebral MRI } \\
\cline { 2 - 3 } & $\begin{array}{c}\text { Normal } \\
\text { (n= 8) }\end{array}$ & $\begin{array}{c}\text { Borderline/ } \\
\text { pathologic } \\
\text { (n = 48) }\end{array}$ \\
\hline Preinduction SBP, mm Hg & $140(21)$ & $155(26)$ \\
Minimum intraoperative SBP, mm Hg & $73(8)$ & $74(10)$ \\
Duration of CPB, min & $56(26)$ & $63(25)$ \\
Aortic crossclamp time, min & $30(11)$ & $36(19)$ \\
Maximum MAP during CPB, mm Hg & $48(10)$ & $56(11)$ \\
Minimum MAP during CPB, mm Hg & $36(4)$ & $37(8)$ \\
Conversion from off-pump surgery & $1(13 \%)^{*}$ & $3(6 \%) \dagger$ \\
Intraoperative epinephrine & $1(13 \%)$ & $3(6 \%)$ \\
MAP <60 mm Hg occurring in & & \\
$\quad$ intensive care on day of operation & $3(38 \%)$ & $11(23 \%)$ \\
Postoperative IABP & $1(13 \%)$ & $0(-)$
\end{tabular}

Values are presented as means (standard deviation) or counts (percentage). MRI, Magnetic resonance imaging; $S B P$, systolic blood pressure; $C P B$, cardiopulmonary bypass; $M A P$, mean arterial blood pressure; $I A B P$, intra-aortic balloon pump. *Conversion from off-pump procedure for hemodynamic instability. †One conversion for hemodynamic instability and 2 for technical reasons.

pump to on-pump procedure, postdischarge adverse events, and life stressors. The final model was also stable when adding intraoperative arrhythmia, hypotension, or the use of inotropes.

Measuring physical and mental health status draws on everyday function as experienced by the patient and can be seen as a high level of integration of health domains, including individual coping mechanisms and environmental support. The SF-36 has demonstrated responsiveness in previous studies of cardiac surgery both to improvement ${ }^{19}$ and decline. ${ }^{20}$ In the present study the physical health component was most sensitive to the interaction phenomenon observed and to relief of angina, whereas our models explained less than $20 \%$ of variance in mental health. Newman and coworkers ${ }^{21}$ did establish a significant multivariable relationship at 5 years after bypass surgery between cognitive function and physical health but not mental health. A study of aortic arch surgery demonstrated that midterm health status, as measured by the SF-36, was related to the duration of deep hypothermic cardiac arrest. Use of antegrade cerebral perfusion separated groups significantly over varying durations of cardiac arrest with regard to the SF-36 subscales of vitality, physical functioning, and social functioning. ${ }^{22}$ Others have found age to be a strong predictor of early $^{23}$ and long-term ${ }^{24}$ postoperative neurocognitive impairment. In the present study age was strongly correlated with preoperative MRI status. However, the analysis indicated separate contributions of age and preoperative MRI findings on change in physical health, with the strongest contribution coming from MRI status. 
It is difficult to explain the mechanisms connecting preoperative evidence of cerebrovascular disease to patientreported outcomes. We did not find similar results in the group without cardiopulmonary bypass, in which manipulation of the heart during off-pump surgery has the potential to cause episodes of hemodynamic instability and critical cerebral hypoperfusion without hypothermic protection. ${ }^{25}$ Previous randomized trials of on-pump versus off-pump bypass surgery have failed to demonstrate significant independent effects of cardiopulmonary bypass on patientreported health status. ${ }^{26-28}$ In the present study no independent statistical effect was observed of new postoperative lesions on self-reported health. This might indicate that the state of the brain before surgical intervention is of greater importance. A possible explanation is the fact that gaseous and solid microemboli enter the brain during cardiac surgery, with a higher number of emboli during on-pump than off-pump surgery. ${ }^{12,29}$ Assuming that patients with preoperative cerebral injury have less tolerance for gaseous or solid emboli, diffuse intraoperative cerebral injury would be more extensive among on-pump patients who are exposed to a greater number of emboli. Diffuse cerebral injury after on-pump surgery might disturb the integrity and speed of neural networks, influencing perception, performance, and the experience of rehabilitation without presenting as neurologic symptoms.

As for any secondary analysis, caution must be exercised in the interpretation of results. This study included patients with a low risk profile from a surgical point of view. Although the number of patients with normal preoperative cerebral MRI was relatively low, change in physical health from baseline was well concentrated in the on-pump group at 3 months (Figure 1). Patients without preoperative angina were evenly distributed regarding the use of cardiopulmonary bypass, as well as baseline MRI status. This reduced the possibility of group bias caused by patients experiencing a relative decrease in health status during rehabilitation. ${ }^{20}$ The amount of missing data at follow-up was low, justifying complete case analysis.

\section{Conclusions}

This study strongly suggests that the combination of preoperative cerebral ischemic injury and use of cardiopulmonary bypass can predict postoperative health status at 3 months. Cerebral MRI might be a more specific indicator than age for preoperative assessment of vulnerability or resilience during rehabilitation after on-pump cardiac surgery.

We thank Torbjørn Moum, PhD, for statistical advice and Bjørn Erik Mørk, MSc, and Ellen Hovland for coordinating study patients. The patients generously shared their experiences and made this study possible. Anonymous data for the population reference norms used in this study are from the Health Status Survey 2002 provided by The Norwegian Social Science Data Services (NSD), with data collection and organization conducted by Statistics Norway. Neither Statistics
Norway nor NSD are responsible for the analyses or interpretations put forth in this article.

\section{References}

1. Schipper H, Clinch JJ, Olweny CLM. Quality of life studies: definitions and conceptual issues. In: Spilker B, editor. Quality of life and pharmacoeconomics in clinical trials. Philadelphia: Lippincott-Raven; 1996. p. 11-23.

2. Khatri P, Babyak M, Clancy C, Davis R, Croughwell N, Newman M, et al. Perception of cognitive function in older adults following coronary artery bypass surgery. Health Psychol. 1999;18:301-6.

3. Keizer AM, Hijman R, Van Dijk D, Kalkman CJ, Kahn RS. Cognitive self-assessment one year after on-pump and off-pump coronary artery bypass grafting. Ann Thorac Surg. 2003;75:835-8.

4. Newman S, Klinger L, Venn G, Smith P, Harrison M, Treasure T. Subjective reports of cognition in relation to assessed cognitive performance following coronary artery bypass surgery. J Psychosom Res. 1989;33:227-33.

5. Bryan RN, Cai J, Burke G, Hutchinson RG, Liao D, Toole JF, et al. Prevalence and anatomic characteristics of infarct-like lesions on MR images of middle-aged adults: the atherosclerosis risk in communities study. AJNR Am J Neuroradiol. 1999;20:1273-80.

6. Newman AB, Gottdiener JS, McBurnie MA, Hirsch CH, Kop WJ, Tracy R, et al. Associations of subclinical cardiovascular disease with frailty. J Gerontol A Biol Sci Med Sci. 2001;56:M158-66.

7. Toner I, Peden CJ, Hamid SK, Newman S, Taylor KM, Smith PL. Magnetic resonance imaging and neuropsychological changes after coronary artery bypass graft surgery: preliminary findings. J Neurosurg Anesthesiol. 1994;6:163-9.

8. Vanninen R, Aikia M, Kononen M, Partanen K, Tulla H, Hartikainen $\mathrm{P}$, et al. Subclinical cerebral complications after coronary artery bypass grafting: prospective analysis with magnetic resonance imaging, quantitative electroencephalography, and neuropsychological assessment. Arch Neurol. 1998;55:618-27.

9. Kohn A. Magnetic resonance imaging registration and quantitation of the brain before and after coronary artery bypass graft surgery. Ann Thorac Surg. 2002;73(suppl):S363-5.

10. Knipp SC, Matatko N, Wilhelm H, Schlamann M, Massoudy P, Forsting $\mathrm{M}$, et al. Evaluation of brain injury after coronary artery bypass grafting. A prospective study using neuropsychological assessment and diffusion-weighted magnetic resonance imaging. Eur J Cardiothorac Surg. 2004;25:791-800.

11. Lingaas PS, Hol PK, Lundblad R, Rein KA, Tonnesen TI, Svennevig $\mathrm{JL}$, et al. Clinical and angiographic outcome of coronary surgery with and without cardiopulmonary bypass: a prospective randomized trial. Heart Surg Forum. 2004;7:37-41.

12. Lund C, Hol PK, Lundblad R, Fosse E, Sundet K, Tennoe B, et al. Comparison of cerebral embolization during off-pump and on-pump coronary artery bypass surgery. Ann Thorac Surg. 2003;76:765-70.

13. Wilson IB, Cleary PD. Linking clinical variables with health-related quality of life. A conceptual model of patient outcomes. JAMA. 1995; 273:59-65.

14. Ware JE, Sherbourne CD. The MOS 36-item short form health survey: I. Conceptual framework and item selection. Med Care. 1992;30:473-83.

15. Ware JE, Kosinski M. SF-36 Physical \& mental health summary scales: a manual for users of version 1. 2 ed. Lincoln, RI: QualityMetric Inc; 2003.

16. Campeau L. Grading of angina pectoris. Circulation. 1976;54:522-3.

17. Ware JE, Snow KK, Kosinski M, Gandek B. SF-36 Health Survey: manual and interpretation guide. Boston: The Health Institute; 1993.

18. Mathisen L, Andersen MH, Hol PK, Lingaas PS, Lundblad R, Rein KA, et al. Patient reported outcome after randomization to on-pump versus off-pump coronary artery surgery. Ann Thorac Surg. 2005;79: 1584-9.

19. Barnason S, Zimmerman L, Anderson A, Mohr-Burt S, Nieveen J. Functional status outcomes of patients with a coronary artery bypass graft over time. Heart Lung. 2000;29:33-46.

20. Pirraglia PA, Peterson JC, Williams-Russo P, Charlson ME. Assessment of decline in health-related quality of life among angina-free 
patients undergoing coronary artery bypass graft surgery. Cardiology. 2003;99:115-20.

21. Newman MF, Grocott HP, Mathew JP, White WD, Landolfo K, Reves JG, et al. Report of the substudy assessing the impact of neurocognitive function on quality of life 5 years after cardiac surgery. Stroke. 2001;32:2874-81.

22. Immer FF, Lippeck C, Barmettler H, Berdat PA, Eckstein FS, Kipfer $\mathrm{B}$, et al. Improvement of quality of life after surgery on the thoracic aorta: effect of antegrade cerebral perfusion and short duration of deep hypothermic circulatory arrest. Circulation. 2004;110(suppl II):II250-5.

23. Djaiani GN, Phillips-Bute B, Blumenthal JA, Newman MF. Chronic exposure to nicotine does not prevent neurocognitive decline after cardiac surgery. J Cardiothorac Vasc Anesth. 2003;17:341-5.

24. Newman MF, Kirchner JL, Phillips-Bute B, Gaver V, Grocott H, Jones $\mathrm{RH}$, et al. Longitudinal assessment of neurocognitive function after coronary-artery bypass surgery. $N$ Engl J Med. 2001;344:395-402.

25. Lund C, Lundblad R, Fosse E, Tonnessen TI, Sundet K, Brucher R, et al. Ventricular fibrillation during off-pump coronary artery bypass grafting: transcranial Doppler and clinical findings. Cerebrovasc Dis. 2001;12:139-41.

26. Van Dijk D, Jansen EW, Hijman R, Nierich AP, Diephuis JC, Moons $\mathrm{KG}$, et al. Cognitive outcome after off-pump and on-pump coronary artery bypass graft surgery: a randomized trial. JAMA. 2002;287:1405-12.

27. Ascione R, Reeves BC, Taylor FC, Seehra HK, Angelini GD. Beating heart against cardioplegic arrest studies (BHACAS 1 and 2): quality of life at mid-term follow-up in two randomised controlled trials. Eur Heart J. 2004;25:765-70.

28. Puskas JD, Williams WH, Mahoney EM, Huber PR, Block PC, Duke PG, et al. Off-pump vs conventional coronary artery bypass grafting: early and 1-year graft patency, cost, and quality-of-life outcomes: a randomized trial. JAMA. 2004;291:1841-9.

29. Abu-Omar Y, Balacumaraswami L, Pigott DW, Matthews PM, Taggart DP. Solid and gaseous cerebral microembolization during offpump, on-pump, and open cardiac surgery procedures. J Thorac Cardiovasc Surg. 2004;127:1759-65.

\section{Authoritative}

The Journal of Thoracic and Cardiovascular Surgery is the most frequently cited thoracic/cardiovascular surgery journal in the Science Citation Index. An article in JTCVS is cited on average almost twice as often as those in the closest cardiothoracic journal. 